\title{
STRATEGI PENGEMBANGAN PARIWISATA BERBASIS SUMBER DAYA ALAM PESISIR DAN LAUT DI PANTAI DEPOK DAERAH ISTIMEWA YOGYAKARTA
}

\section{Develompment Strategy of Tourism Activity Base on Coastal and Marine Resources in Depok Beach, Daerah Istimewa Yogyakarta}

\author{
*Agustina Setyaningrum, Heny Budi Setyorini dan Edy Masduqi \\ Fakultas Teknologi Sumber Daya Alam, Institut Teknologi Yogyakarta \\ Jl. Gedong Kuning No.2, Banguntapan, Kota Yogyakarta,Daerah Istimewa Yogyakarta, Indonesia \\ Diterima tanggal: 21 Februari 2017 Diterima setelah perbaikan: 26 Oktober 2017 \\ Disetujui terbit: 12 Desember 2017 \\ *email: agustinasetya@gmail.com
}

\begin{abstract}
ABSTRAK
Kawasan pariwisata Pantai Depok dewasa ini mulai dikenal luas oleh masyarakat. Selama ini tempat wisata ini dikenal dengan wisata kulinernya. Sumber daya alam pesisir dan laut yang ada di Pantai Depok beragam baik itu sumber daya hayati maupun sumber daya non hayati. Tujuan dari penelitian ini adalah untuk merumuskan strategi pengembangan pariwisata berbasis sumber daya alam pesisir dan laut di Pantai Depok. Data yang digunakan dalam penelitian ini meliputi data primer dan data sekunder. Teknik Rapid Rural Apraisal digunakan dalam penelitian ini. Keberagaman sumber daya alam pesisir dan laut dapat menjadi salah satu daya tarik wisata baru di Pantai Depok. Salah satunya adalah dengan pengolahan produk hasil kelautan. Produk tersebut perlu dimaksimalkan agar produk tersebut memiliki nilai tambah dan nilai jual yang tinggi. Pengolahan produk hasil kelautan ini dapat dijadikan sebagai produk unggulan baru yang mendukung kegiatan pariwisata di Pantai Depok.
\end{abstract}

Kata Kunci: sumber daya, pariwisata, nilai tambah

\begin{abstract}
Depok Beach tourism area today is becoming widely known by the public. This tourist spot known as culinary tour. The coastal and marine natural resources in Depok Beach are both biological and nonbiological resources. The purpose of this research is to formulate coastal and marine natural resourcebased tourism development strategy in Depok Beach. Data used in this research include primary data and secondary data. Rapid Rural Apraisal techniques were used in this study. The diversity of coastal and marine natural resources can be one of the new tourist attraction in Depok Beach. One of them is the processing of marine products. The product needs to be maximized so that the product has added value and high selling value. Processing of marine products can be used as a new flagship product that supports tourism activities in Depok Beach.
\end{abstract}

Keywords: marin resources, tourism activity, vallue added

\section{PENDAHULUAN}

Kawasan Pantai Selatan, Kabupaten Bantul meliputi wilayah Kecamatan Srandakan, Kecamatan Sanden dan Kecamatan Kretek. Kawasan ini menjadi penting dan strategis, karena memiliki berbagai potensi, seperti kekayaan sumber daya, Lokasi Destinasi Wisata (LDW) Pantai, Jalur Jalan Pantai Selatan (Pansela), tower-tower operator telepon seluler (BTS), tempat pelelangan ikan (TPI), kincir angin pembangkit energi, dan lain-lain. Selain potensi tersebut, Kawasan Pantai Selatan (Pansela) Kabupaten Bantul memiliki beberapa pantai yang cukup terkenal, antara lain Pantai
Pandansimo, Pantai Kwaru, Pantai Samas, Pantai Depok, Pantai Parang Kusumo sampai Pantai Parangtritis.

Pantai Depok dikenal oleh kalangan luas, karena memadukan berbagai kegiatan dalam satu kawasan. Kawasan wisata ini merupakan kawasan wisata bahari. Wisata bahari memanfaatkan potensi lingkungan pantai sebagai daya tarik wisatanya (Nawawi, 2013). Atraksi wisata bahari tersebut antara lain pemandangan pantai yang indah, pendaratan ikan, pelelangan ikan, penjualan ikan, kuliner berbahan ikan, atraksi pesawat ringan, festival layangan, penjualan souvenir dan lainnya. 
Pantai Depok memiliki sumber daya laut, yang cukup melimpah untuk lebih berkembang sebagai wisata bahari.

Banyaknya event pariwisata dan semakin ramainya kawasan wisata Pantai Depok menunjukkan semakin berkembangnya kegiatan pariwisata yang ada disana. Peningkatan kegiatan pariwisata merupakan salah satu cara untuk meningkatkan kondisi ekonomi masyarakat. Apabila suatu obyek wisata ramai dikunjungi oleh wisatawan maka kesejahteraan masyarakat yang bergantung pada kegiatan pariwisata akan meningkat. Untuk mewujudkan kegiatan pariwisata yang berkelanjutan, maka seharusnya dapat didukung oleh sumber daya lokal yang ada disana. Hal ini sejalan dengan definisi parwisata berkelanjutan oleh United Nations World Tourism Organization (UNWTO) (2011) yang menyebutkan bahwa pariwisata yang memperhitungkan dampak sosial, ekonomi dan lingkungan saat ini dan masa mendatang dengan memenuhi kebutuhan pengunjung, industri, lingkungan dan masyarakat setempat. Oleh karena itu, sumber daya kelautan yang ada di Pantai Depok dapat dimanfaatkan untuk mendukung aktivitas pariwisata bahari. Nilai perekonomian dari hasil laut disana juga sangat besar. Nilai ekonomi sumber daya perikanan dan jasa-jasa lingkungan di Pantai Depok mencapai Rp 58,725 milyar (Sahubawa, 2015). Nilai ini juga termasuk dalam kegiatan pariwisata.

Kegiatan pariwisata kuliner di Pantai Depok sangat berkembang, meskipun demikian kebutuhan ikan banyak dipasok dari daerah lain seperti Semarang, Cilacap dan Pacitan (Haryanti et al., 2015). Penangkapan ikan yang berasal dari Pantai Depok masih terbatas, sehingga harus mendatangkan ikan dari daerah lain. Sumber daya hayati lainnya juga belum dimaanfaatkan secara maksimal. Kondisi Pantai Depok cukup panas, sehingga perlu ditanami tanaman agar rindang. Demikian halnya dengan pemanfaatan lahan di Pantai Depok, hamparan pasir luas bisa dimanfaatkan sebagai arena bermain dan juga arena untuk bersantai bagi keluarga. Di Pantai Depok, lahan kosong masih banyak dan belum dimanfaatkan secara maksimal.

Undang-Undang No.10 Tahun 2009 tentang Kepariwisataan, menyebutkan bahwa wisata merupakan kegiatan perjalanan yang dilakukan oleh seseorang atau sekelompok orang dengan mengunjungi tempat tertentu untuk tujuan rekreasi, pengembangan pribadi, atau mempelajari keunikan daya tarik wisata yang dikunjungi dalam jangka waktu sementara. Aktivitas pariwisata digerakkan oleh dua kekuatan utama yaitu permintaan dan penawaran (Gambar 1). Dalam permintaan terdapat minat dan kemampuan wisatawan sedangkan dalam penawaran terdapat semua komponen fisik dan program pengembangan yang diperlukan untuk melayani wisatawan. Dalam kasus ini, pemanfaatan sumber daya alam pesisir dan laut dapat menjadi daya tawar tersendiri bagi pengembangan suatu obyek wisata bahari. Hal ini juga didukung oleh pernyataan Fandeli (2002) yang menyebutkan bahwa kegiatan pariwisata yang berbasis sumber daya menyebabkan potensi produk wisata alam memiliki daya tawar dan daya saing yang tinggi.

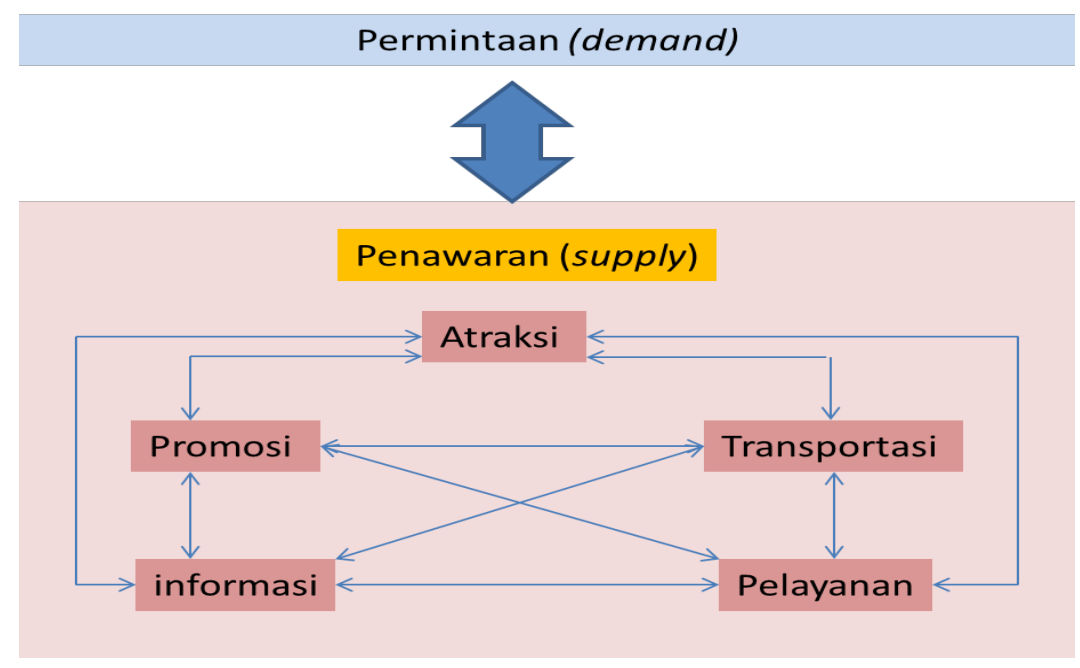

Gambar 1. Pariwisata Sebagai Suatu Sistem.

Figure 1. Tourism As a System.

Sumber: Gunn, 2002 dalam Saputra, 2010/Source : Gunn, 2002 in Saputra, 2010 
Pengolahan suatu produk barang/jasa dianggap mampu meningkatkan nilai tambahnya dari pada hanya dijual tanpa adanya pengolahan. Nilai tambah merupakan pertambahan nilai suatu produk barang/jasa karena mengalami proses pengolahan dalam suatu proses produksi. Supriyati dan Tarigan (2008) menyebutkan bahwa terdapat lima alasan pentingnya pengolahan suatu produk barang/jasa antara lain (1) industri pengolahan mampu mengubah keunggulan komparatif menjadi keungguan kompetitif, sehingga daya saing produk yang dihasilkan semakin meningkat; (2) produk hasil olahan memiliki nilai tambah yang dapat meningkatkan perekonomian; (3) pengolahan suatu produk dianggap mampu mempengaruhi sektor lain karena adanya keterkaitan dari hulu ke hilir; (4) terdapat bahan baku sehingga berkelanjutan dan; (5) berpeluang mengubah struktur ekonomi dari pertanian ke industri.

Pengolahan terhadap sumber daya alam peisisir dan laut belum dilakukan secara optimal. Dahuri et al. (2004), menjelaskan bahwa sumberdaya alam di wilayah pesisir dan laut Indonesia meliputi sumberdaya alam yang dapat pulih (renewable resources) seperti sumberdaya perikanan (plankton, benthos, ikan, moluska, krustasea, mamalia laut), rumput laut, padang lamun, hutan mangrove dan terumbu karang; dan sumberdaya yang tidak dapat pulih (unrenewable resources) seperti minyak dan gas, bijih besi, pasir, timah, bauksit dan mineral serta berbagai jenis bahan tambang yang lain.

Tujuan dari penelitian ini adalah untuk merumuskan strategi pengembangan pariwisata berbasis sumber daya alam pesisir dan laut di Pantai Depok. Perumusan strategi ini didasarkan pada potensi dan peluang yang ada disana. Masih banyak sumber daya alam yang dijual langsung dan belum dilakukan pengolahan. Apabila sumber daya tersebut diolah dan disinergikan dengan aktivitas yang lain misalnya aktivitas pariwisata, maka produk tersebut akan memiliki nilai tambah dan mampu memberikan peran yang penting bagi pertumbuhan ekonomi lokal dan nasional.

\section{METODOLOGI}

Penelitian ini dilaksanakan pada tahun 2016 dengan skema penelitian dosen dan mahasiswa. Tabel pelaksanaan penelitian disajikan pada Tabel 1. Lokasi penelitian di Pantai Depok Kabupaten Bantul Daerah Istimewa Yogyakarta. Pendekatan yang digunakan dalam penelitian ini adalah pendekatan kualitatif. Alat dan bahan yang digunakan dalam survey lapangan penelitian ini antara lain kamera, serta alat bantu daftar pertanyaan.

\section{Tabel 1. Waktu Pelaksanaan Penelitian.}

\section{Table 1. Time of Research.}

\begin{tabular}{|c|c|c|c|c|c|c|}
\hline \multirow[b]{2}{*}{ No } & \multirow{2}{*}{$\begin{array}{l}\text { Uraian Kegiatan/ } \\
\text { Description of Activities }\end{array}$} & \multicolumn{5}{|c|}{2016} \\
\hline & & $\begin{array}{l}\text { Mei/ } \\
\text { May }\end{array}$ & $\begin{array}{l}\text { Juni/ } \\
\text { June }\end{array}$ & $\begin{array}{l}\text { Juli/ } \\
\text { July }\end{array}$ & $\begin{array}{l}\text { Agustus/ } \\
\text { August }\end{array}$ & $\begin{array}{l}\text { Septemberl } \\
\text { September }\end{array}$ \\
\hline 1 & $\begin{array}{l}\text { Observasi awal lokasi penelitian/ Observation of initial } \\
\text { research location }\end{array}$ & & & & & \\
\hline 2 & Pengumpulan data sekunder/Secondary data collection & & & & & \\
\hline 3 & Persiapan lapangan /Field preparation & & & & & \\
\hline 4 & $\begin{array}{l}\text { Pengambilan data lapangan / Field data retrieval } \\
\text { a. Pengamatan lapangan: melakukan kajian } \\
\text { potensi sumber daya hayati dan non hayati/ Field } \\
\text { observation: undertook a study of biological and non- } \\
\text { biological resources }\end{array}$ & & & & & \\
\hline & $\begin{array}{l}\text { b. Wawancara mendalam dengan informan kunci } \\
\text { (pedagang)/ In-depth interviews with key informants } \\
\text { (traders) }\end{array}$ & & & & & \\
\hline & $\begin{array}{l}\text { c. Wawancara dengan pengunjung/Interview with } \\
\text { visitors }\end{array}$ & & & & & \\
\hline 5 & Pengolahan data lapangan/Processing of field data & & & & & \\
\hline 6 & Analisis data lapangan/Analysis of field data & & & & & \\
\hline 7 & $\begin{array}{l}\text { Penyusunan strategi kebijakan/ Preparation of a policy } \\
\text { strategy }\end{array}$ & & & & & \\
\hline 8 & $\begin{array}{l}\text { Penyusunan laporan penelitian/ Preparation of } \\
\text { research reports }\end{array}$ & & & & & \\
\hline
\end{tabular}


Data yang digunakan dalam penelitian ini meliputi data primer dan data sekunder. Data primer diperoleh secara langsung dari lapangan baik itu melalui wawancara mendalam dengan pedagang dan pengunjung yang ditemui di lokasi serta melakukan observasi secara langsung dilapangan dengan menggunakan teknik Rapid Rural Appraisal (RRA). Jumlah informan disajikan dalam Tabel 2. Data sekunder yang digunakan dalam penelitian ini meliputi data hasil kajian/penelitian sebelumnya serta data/informasi yang diperoleh dari lembaga/instansi terkait.

Data yang sudah diperoleh dari lapangan kemudian dianalasis dengan menggunakan analisis deskriptif dan juga analisis SWOT (Stenght, Weakness, Opportunity and Threat). Analisis SWOT digunakan untuk menyusun strategi dan kebijakan pengembangan pariwisata di Pantai Depok berbasis sumber daya kelautan.

\section{HASIL DAN PEMBAHASAN}

\section{Aktivitas Pariwisata dan Kebutuhan Ikan di Pantai Depok}

Pengembangan pariwisata berbasis sumber daya alam di Indonesia harus mengedepankan segi kualitas dibanding kuantitas, hal ini disebabkan karena apabila sebuah Obyek dan Daya Tarik
Wisata (ODTW) alam diketahui memiliki kualitas yang bagus maka akan memiliki daya jual yang tinggi (Fandeli, 2002). Demikian halnya dengan aktivitas pariwisata di Pantai Depok, yang selama ini dikenal dengan wisata kulinernya, akan lebih baik apabila sumber daya kelautan yang ada disana juga mampu mendukung kegiatan pariwisata yang ada.

Banyak masyarakat yang berkunjung ke Pantai Depok dengan alasan untuk melakukan wisata kuliner, sekedar untuk jalan-jalan dan menikmati wisata pantai. Hal ini didukung oleh pernyataan responden berikut ini.

'Saya datang ke Pantai Depok ini untuk berwisata kuliner dan untuk jalan-jalan'. (A8)

'Selain wisata kuliner dan jalan-jalan, saya ke sini untuk menikmati wisata pantai'. (A12)

'Saya main ke Pantai Depok ini untuk wisata kuliner dan juga ingin main ke gumuk pasir'. (A9)

Namun, ada juga yang berwisata ke Pantai Depok karena memang pilihan dari suatu lembaga/perusahaan untuk berwisata di Pantai Depok dan bukan merupakan pilihan dari wisatawan itu sendiri. Pernyataan ini diungkapkan oleh responden berikut ini.

Tabel 2. Jumlah Informan.

Table 2. Number of Informans.

\begin{tabular}{llc}
\hline No & Informan kunci/Key Informant & Jumlah/Total \\
\hline 1 & Pedagang/Seller & 11 \\
2 & Wisatawan/Tourist & 13 \\
\hline
\end{tabular}

Tabel 3. Data Sekunder yang Digunakan Dalam Penelitian.

Tabel 3. Secondary Data Which Use in Research.

\begin{tabular}{lll}
\hline No & \multicolumn{1}{c}{ Data Sekunder/ Secondary Data } & \multicolumn{1}{c}{ Sumber/ Source } \\
\hline 1 & $\begin{array}{l}\text { Kabupaten Bantul Dalam Angka 2010-2013/ Bantul } \\
\text { District In Figures 2010-2013 }\end{array}$ & $\begin{array}{l}\text { BPS Kabupaten Bantul/ BPS of } \\
\text { Bantul Regency }\end{array}$ \\
2 & $\begin{array}{l}\text { Laporan Penelitian Karakteristik Nelayan Di Pantai } \\
\text { Depok, Bantul, Yogyakarta/ Research Report on Fishers' } \\
\text { Characteristics In Depok Beach, Bantul, Yogyakarta }\end{array}$ & $\begin{array}{l}\text { Prodi Teknik Kelautan ITY/ Marine } \\
\text { Engineering Program ITY }\end{array}$ \\
3 & $\begin{array}{l}\text { Laporan Penelitian Sumber Daya Kelautan untuk } \\
\text { Menunjang Kegiatan Pariwisata di Pantai Depok Daerah }\end{array}$ & $\begin{array}{l}\text { Prodi Teknik Kelautan ITY/ Marine } \\
\text { Engineering Program ITY }\end{array}$ \\
& $\begin{array}{l}\text { Istimewa Yogyakarta/ Marine Resource Research Report } \\
\text { to Support Tourism Activities in Depok Beach Special }\end{array}$ & \\
& $\begin{array}{l}\text { Region of Yogyakarta } \\
\text { Laporan Penelitian Studi Kebutuhan Ikan di Pantai Depok }\end{array}$ & \\
& $\begin{array}{l}\text { Yogyakarta.Yogyakarta/ Research Report Study of Fish in } \\
\text { Depok Beach Yogyakarta. Yogyakarta }\end{array}$ & Engineering Program ITY \\
\end{tabular}


'Saya ke Pantai Depok karena ini merupakan piknik dari perusahaan'. (A1)

'Karena ini adalah liburan dari perusahaan jadi asal ikut'. (A3)

Terdapat juga masyarakat yang ke Pantai Depok dengan alasan hanya mampir, seperti ungkapan responden berikut ini.

'Kami ke pantai Depok hanya mampir, karena tadi ada urusan disekitar sini'. (A2)

'Kami baru saja dari rumah saudara, kemudian setelah itu kami mampir ke Pantai Depok'. (A7)

Beragam alasan masyarakat untuk mengunjungi Pantai Depok. Berdasarkan dari kunjungan yang mereka lakukan, mereka memiliki masukan untuk pengembangan pariwisata di Pantai Depok. Banyak yang beranggapan kebersihan di Pantai Depok harus ditingkatkan dan penataan kawasan Pantai Depok harus segera dilakukan agar tidak terkesan berantakan. Berikut pernyataan beberapa responden.

'Pantainya kurang bersih sehingga kebersihan pantai harus ditingkatkan'. (A1)

'Perlu penataan karena kurang teratur dan kebersihan pantai harus ditingkatkan'.(A2)

'Kebersihan perlu ditingkatkan'.(A4)

'Kebersihan toilet ditingkatkan'. (A11)

Tidak hanya memberikan masukan untuk peningkatan kebersihan, mereka juga memberikan masukan terkait dengan sarana dan prasarana untuk meningkatkan kebersihan di Pantai Depok, seperti yang diungkapkan oleh responden berikut ini.

'Fasilitas kebersihan ditambah, toilet sudah cukup bersih'. (A7)

'Sarana dan prasarana persampahan ditingkatkan'. (A8)

'Sarana dan prasarana persampahan dan tempat bermain masih kurang'.(A9)

Tabel 4. Produksi Ikan di Pantai Depok. Table 4. Fish Production in Depok Beach.
Terkait dengan penataan kawasan Pantai Depok. Terdapat beberapa masukan dari wisatawan terkait dengan penambahan insfrastruktur pendukung aktivitas pariwisata. Beberapa berpendapat agar di Pantai Depok ada tempat untuk berteduh sehingga mereka dapat menikmati keindahan Pantai. Berikut pernyataan dari responden.

'Kurang rapi, kurang bersih dan kurang pemandu wisatanya'. (A5)

'Ditambah tempat duduk, parkiran ditata agar lebih rapi dan masjid harus lebih bersih lagi'. (A6)

'Membangun sarana dan prasarana untuk bermain anak-anak seperti kidsfun'.(A12)

'Diberi payung untuk berteduh, untuk tempat nongkrong dan ditambah kursi untuk berjemur'. (A13)

Minat masyarakat cukup tinggi untuk berpariwisata di Pantai Depok. Berdasarkan penelitian yang dilakukan oleh Haryanti, et al. (2015) aktivitas pariwisata ini sangat ramai ketika hari libur dan weekend (Haryanti et al., 2015), meskipun demikian untuk mendukung wisata kuliner disana, pasokan ikan banyak didatangkan dari daerah lain antara lain Semarang, Cilacap dan lain sebagainya (Tabel 5). pada saat aktivitas pariwisata ramai setiap pedagang ikan mampu menjual hingga 1 kwintal, namun pada hari-hari biasa hanya berkisar 10-30 kg (Haryanti et al., 2015). Apabila melihat pada produksi perikanan, produksi ikan di Pantai Depok dari tahun 2010 hingga tahun 2012, produksi ikan mengalami peningkatan. Meskipun mengalami peningkatan produksi ikan, beberapa jenis ikan seperti Layur dan Bawal dibawa keluar daerah karena kurang diminati oleh konsumen terutama wisatawan yang berkunjung ke Pantai Depok (Haryanti et al., 2015). Tabel produksi ikan dapat dilihat pada Tabel 4.

\begin{tabular}{cc}
\hline Tahun/ Year & Produksi/ Production $(\mathbf{K g})$ \\
\hline 2008 & 81,502 \\
2009 & 138,736 \\
2010 & 185,328 \\
2011 & 182,897 \\
2012 & 283,248 \\
\hline
\end{tabular}

Sumber: Kabupaten Bantul Dalam Angka 2010-2013 (Haryanti et al., 2015)/

Source : Bantul Regency in Figures 2010-2013 (Haryanti et al., 2015) 
Tabel 5. Asal Pasokan lkan.

Table 5. The Origin of Fish Supply.

\begin{tabular}{|c|c|}
\hline Jenis Ikan/ Kinds of Fish & Asal/ Origin \\
\hline Kerang darah (Anadara granosa), kerang hijau (Mytilus edulis), & Semarang \\
\hline $\begin{array}{l}\text { Surung (Eleutheronema tetradactylum), layur (Trichiurus lepterus), kuwe } \\
\text { (Caranx sexfasciatus), pari (Aetomylaeus nichofii), kakap merah (Lutjanus } \\
\text { campechanus), tenggiri (Scomberomorus plumierii), Bawal putih (Pampus } \\
\text { argenteus), kakap putih (Lates calcarifer), hiu (Carcharodon carcharias), } \\
\text { rajungan (Portunus pelagicus), cakalang (Katsuwonus pelamis), tongkol } \\
\text { (Thunnus tonggol), udang jerbung (Fenneropenaeus merguiensis), udang } \\
\text { dogol (Metapenaeus monoceros) cumi-cumi (Loligo sp), }\end{array}$ & Pantai Depok \\
\hline Kembung (Resterelinger kanagurta/ Rastrelliger brachysoma), & Cilacap \\
\hline Tuna (Thunnus albacares), tongkol (Thunnus tonggol), & Pacitan \\
\hline Kepiting (Scylla serrata) & Kalimantan \\
\hline Kakap putih (Lates calcarifer), kakap merah (Lutjanus campechanus) & Pantai Baron \\
\hline
\end{tabular}

Sumber: Haryanti et al. (2015) dan Setyorini et al. (2015)/Source: Haryanti et al. (2015) and Setyorini et al. (2015)

Jenis ikan layur dan bawal yang belum banyak diminati di Pantai Depok, dapat diolah lagi sehingga memiliki nilai jual dan mendukung kegiatan pariwisata di Pantai Depok.

Aktivitas pariwisata di Pantai Depok selama ini dikelola oleh Koperasi Wisata Mina Bahari 45 yang merupakan wadah organisasi masyarakat yang ada di Dusun Depok. Organisasi mengelola kegiatan pariwsata, kegiatan ekonomi dan kegiatan sosial lainnya (Nawawi, 2013). Banyak warga yang tergabung dalam koperasi ini dan mereka sangat terbantu dalam mengembangkan usaha wisatanya karena adanya koperasi ini. Berikut salah satu pernyataan warga yang menjadi anggota koperasi.

'Untuk meningkatkan pendapatan saya menambah stok ikan, udang dan jualan buah pisang. Selain itu saya menjadi anggota koperasi dan bisa meminjam bahan-bahan untuk jualan seperti minyak goreng, tepung dan lain-lain'. (B2).

Berdasarkan pada pernyataan tersebut, pedagang sangat terbantu dan dapat menjalankan usahanya dengan baik.

\section{Strategi Pengembangan Pariwisata di Pantai Depok}

\section{a. Potensi dan Peluang Pengembangan Wisata Pantai Depok}

Sumber daya kelautan di Pantai Depok cukup beragam. Setyorini et al., (2016) menyebutkan sumber daya hayati Pantai Depok meliputi tanaman pantai, dan, berbagai jenis ikan dan krustasea serta sumber daya non hayati meliputi pasir, gelombang, angin dan air laut. berikut disajikan pada Tabel 6 sumber daya kelautan di Pantai Depok.

Aktivitas pariwisata, perikanan dan kegiatan lainnya dikendalikan oleh Koperasi Wisata Mina Bahari 45 (Nawawi A, 2013). Koperasi ini menjadi pengendali dan pengontrol seluruh aktivitas yang ada di Pantai Depok. Anggota kopearasi ini terdiri dari nelayan dan pedagang -pedagang yang ada di Pantai Depok. Selain tergabung dalam koperasi tersebut terdapat juga masyarakat yang tergabung dalam Kelompok Usaha Bersama (KUB) Mina bahari 45. KUB Mina Bahari 45 terdiri dari pengusaha-pengusaha pengolah ikan, pengusaha warung makan, penjual ikan dan usaha-usaha lainnya.

Deretan pantai yang ada di sepanjang pesisir selatan DIY menjadi daya tarik sendiri bagi wisatawan untuk datang ke sana. Hal ini juga menjadi salah satu faktor yang menyebabkan ramainya kunjungan wisatawan ke Pantai Depok. Deretan pantai yang ada di sekitar Pantai Depok antara lain Pantai Parangtritis, Pantai Parangkusumo dan Pantai Pelangi. Dukungan pemerintah setempat juga sangat tinggi dalam pengembangan obyek wisata di Pantai Depok. Kondisi ini ditunjukkan dengan adanya festival tahunan yang diselenggarakan di Pantai Depok antara lain Jogja International Air Show dan Festival Perahu Naga. Penyelenggaraan event tahunan tersebut mampu menarik banyak wisatawan untuk datang ke Pantai Depok. 
Tabel 6. Sumber Daya Alam Pesisir dan Laut di Pantai Depok. Table 6. Coastal and Marine Resource in Depok Beach.

\begin{tabular}{ccc}
$\begin{array}{c}\text { Sumber Daya/ } \\
\text { Resources }\end{array}$ & $\begin{array}{c}\text { Pemanfaatan/ } \\
\text { Utilization }\end{array}$ & $\begin{array}{c}\text { Pengolahan/ } \\
\text { Processing }\end{array}$ \\
\hline
\end{tabular}

Sumber Daya Hayati/ Biological Resources

Tanaman Pantai/ Coastal Plants

a. Cemara udang (Casuarina equisetifolia)

b. Ketapang (Terminalia catappa)
Fungsi secara ekologis sebagai sabuk hijau pantai dan penahan laju abrasi, sedangkan fungsi secara estetika sebagai salah satu pemandangan alam dan tempat berteduh bagi wisatawan/ Ecologically functioning as a coastal green belt and abrasion rate holder, while aesthetically functioning as one of nature's scenery and shelter for tourists

Ikan/ Fishes

a. Bawal (Pampus argenteus)

b. Cakalang (Katsuwonus Pelamis)

c. Tenggiri (Scomberomorus Commersoni)

Krustasea/ Crustacea

a. Undur-undur

b. Rajungan/ Crab

c. Kepiting/ Crab

d. Udang/ Shrimp
- Wisata kuliner dalam produk olahan goreng kering sebagai oleh-oleh maupun dalam bentuk berbagai jenis masakan yang dapat dinikmati secara langsung di warung-warung yang telah tersedia/ Culinary tour in dried fried processed products as souvenir or in the form of various types of cuisine that can be enjoyed directly in the stalls that have been available

- Wisata kuliner dalam produk olahan goreng kering sebagai oleh-oleh maupun dalam bentuk berbagai jenis masakan yang dapat dinikmati secara langsung di warung-warung yang telah tersedia/ Culinary tour in dried fried processed products as souvenir or in the form of various types of cuisine that can be enjoyed directly in the stalls that have been available

Sumber daya non hayati/ Non biological resources

\section{Pasir/ Sands}

- Berwarna cenderung gelap/ Color tends to be dark

- Berukuran halus/ Fine-sized

Gelombang/ Wave Sea

Angin/ Wind

Air Laut/ Sea water
- Gundukan pasir di sekitar pantai menjadi ekosistem gumuk pasir (sand dune)/ Sand dune around the coast becomes a sand dune ecosystem (sand dune)

- Arena bermain ATVI ATV playground

Pemandangan alam/ Panorama

Paralayang atau Jogja Air Show/

Paragliding or Jogja Air Show

Pemandangan alam/ Panorama

Sumber: Setyorini et al., 2016/Source: Setyorini et al., 2016 


\section{b. Kelemahan dan Tantangan}

Sumber daya hayati yang ada di Pantai Depok belum banyak diolah menjadi produk yang memiliki nilai jual yang tinggi. Hasil tangkapan nelayan umumnya langsung dijual kepada wisatawan atau dijual di TPI. Pengolahan yang sudah dilakukan adalah dengan mengolah ikan menjadi kripik ikan. Belum ada pengolahan yang memiliki nilai ekonomis yang lebih tinggi lainnya seperti pengolahan menjadi frozen food.

Sumber daya non hayati seperti angin belum dimanfaatkan. Angin bisa dimanfaatkan menjadi sumber energi baru terbarukan. Untuk ruang kosong masih bisa dimanfaatkan sebagai ruang terbuka hijau, wahana permainan, taman bermain atau tempat untuk bersantai lainnya. Penambahan atraksi di Pantai Depok bisa menjadi salah satu magnet untuk menarik wisatawan.

Kebutuhan ikan yang tinggi di Pantai Depok selama ini masih dipasok dari daerah lain. Jumlah nelayan masih relatif sedikit di Pantai Depok, sehingga kebutuhan ikan untuk aktivitas pariwisata masih dipasok dari wilayah lain (Haryanti et al., 2015). Sedangkan untuk nelayan yang menangkap ikan di Pantai Depok, mereka mengkap ikan tergantung pada cuaca. Apabila gelombang tinggi nelayan tidak melaut dan atau ketika hari raya banyak nelayan cilacap yang mudik sehingga tangkapan ikan menurun.

\section{c. Analsis Swot}

Penyusunan strategi pengembangan pariwisata berbasis sumber daya kelautan di Pantai Depok menggunakan analisis SWOT (Strenght, Weakness, Opportunity, Threat) yang terdapat dalam Tabel 7.

Berdasarkan pada analisis SWOT diatas maka, strategi strenght-opportunity (SO), weaknessopportunity (WO), strenght-threat (ST) dan strategi weakness-threat (WT) adalah sebagai berikut pada Tabel 8. Strategi tersebut diharapkan mampu digunakan sebagai referensi dalam pengembangan pariwisata yang berbasis pada pengembangan sumber daya pesisir dan laut di Pantai Depok.

Berdasarkan pada analisis terhadap strategi SO-WO-ST-WT, maka strategi pengembangan sebagai berikut:

1. Keberagaman sumber daya hayati dan non hayati dapat dikembangkan untuk menarik banyak wisatawan agar berkunjung ke Pantai Depok.

Tabel 7. Analisis SWOT.

Table 7. SWOT Analysis.

\section{Strenght}

1. Pantai Depok memiliki sumber daya hayati dan non hayati yang cukup beragam/ Depok Beach has biological and biological resources that are quite diverse

2. Terdapat koperasi yang mewadahi aktivitas pariwisata disana/ There is a cooperative that accommodate tourism activities there

\section{Weakness}

1. Sumber daya hayati belum banyak diolah menjadi produk yang memiliki nilai jual yang lebih tinggi/ Biological resources have not been much processed into products that have higher selling value

2. Sumber daya non hayati belum dikembangkan secara optimal/ Non-biological resources have not been developed optimally

3. Pantai Depok belum tertata secara maksimal dan Kebersihan pantai yang masih kurang/ Depok beach has not been arranged to the maximum and the cleanliness of the beach is still lacking

\section{Threath}

1. Mulai dikenal luas oleh masyarakat/ Start widely known by the community

2. Bersinergi dengan obyek wisata lainnya yaitu Pantai Parangtritis dan pantai-pantai yang ada di sekitar Pantai Depok/ Synergize with other attractions of Parangtritis Beach and the beaches that exist around Depok Beach

3. Adanya dukungan dari pemerintah setempat/ Support from local government
1. Ketergantungan sumber daya ikan dari daerah lain/ Dependency of fish resources from other regions

2. Penangkapan ikan tergantung pada cuaca/ Fishing depends on the weather 
Tabel 8, Strategi SWOT.

Table 8. SWOT Strategy.

\section{Strategi SO}

Strategi WO

1. Keberagaman sumber daya hayati dan non hayati dapat dikembangkan untuk menarik banyak wisatawan agar berkunjung ke Pantai Depok/ Diversity of biological and non biological resources can be developed to attract many tourists to visit Depok Beach

2. Mengembangkan icon wisata dari sumber daya yang ada di Pantai Depok untuk meningkatkan aktivitas pariwisata/ Develop a tourist icon from the resources in Depok Beach to increase tourism activities

3. Pemerintah setempat harus mendorong dan membantu pembangunan daya tarik wisata baru dari sumber daya hayati maupun non hayati yang ada di Pantai Depok/ Local government should encourage and assist the development of new tourist attraction from biological and non biological resources in Depok Beach
1. Pengolahan produk sumber daya hayati dilaksanakan oleh anggota koperasi dan didukung oleh pemerintah setempat melalui pelatihan/bantuan alat dan bahan/ kemudahan pinjaman/ Processing of biological resources products implemented by members of cooperatives and supported by local government through training / aid tools and materials / ease of lending

2. Masyarakat setempat melalui koperasi berkerja sama secara bergotong royong menjaga kebersihan Pantai Depok dengan memberikan himbauan-himbauan kepada wisatawan untuk turut menjaga kebersihan pantai/ Local communities through cooperatives work together in mutual cooperation to maintain the cleanliness of Depok Beach by giving appeals to tourists to help keep the beach clean

3. Pemerintah melakukan penataan Kawasan Pantai Depok/ The Government undertakes structuring of Depok Beach Area

\section{Strategi ST} Strategi WT

1. Melakukan budidaya terhadap jenis ikan tertentu/ Conducting cultivation of certain types of fish
1. Melakukan pengolahan terhadap sumber daya hayati tertentu untuk dijadikan sebagai produ unggulan baru/ Processing of certain biological resources to serve as a new superior product

Sumber: Analisis, 2016/Source: Analysis, 2016

2. Mengembangkan icon wisata dari sumber daya yang ada di Pantai Depok untuk untuk dijadikan sebagai produk unggulan baru.

3. Pemerintah setempat harus mendorong dan membantu pembangunan daya tarik wisata baru dari sumber daya hayati maupun non hayati yang ada di Pantai Depok.

4. Pengolahan produk sumber daya hayati dilaksanakan oleh anggota koperasi dan didukung oleh pemerintah setempat melalui pelatihan/bantuan alat dan bahan/kemudahan pinjaman.

5. Masyarakat setempat melalui koperasi berkerja sama secara bergotong royong menjaga kebersihan Pantai Depok dengan memberikan himbauan-himbauan kepada wisatawan untuk turut menjaga kebersihan pantai.

6. Pemerintah melakukan penataan Kawasan Pantai Depok.
7. Melakukan budidaya terhadap jenis ikan tertentu.

\section{KESIMPULAN DAN IMPLIKASI KEBIJAKAN}

\section{Kesimpulan}

Sumberdaya kelautan di Pantai Depok baik sumberdaya hayati maupun sumberdaya non hayati sangat beragam dan memiliki potensi untuk dikembangkan sebagai daya tarik beru aktivitas pariwisata di Pantai Depok. Pengolahan produk hasil kelautan perlu dimaksimalkan agar produk tersebut memiliki nilai tambah dan nilai jual yang tinggi. Pengolahan produk hasil kelautan yang akan dilakukan oleh masyarakat ini dapat dijadikan sebagai produk unggulan baru yang mendukung kegiatan pariwisata di Pantai Depok. Banyaknya kelompok masyarakat yang ada disana akan memudahkan untuk implementasi kegiatan tersebut. 


\section{Implikasi Kebijakan}

Berdasarkan pada strategi yang sudah disusun sebelumnya, maka dapat dirumuskan kebijakan untuk mengembangkan pariwisata berbasis sumber daya alam pesisir dan laut di Pantai Depok sebagai berikut pada Tabel 9.

\section{UCAPAN TERIMA KASIH}

Terima kasih diucapkan kepada Program Studi Teknik Kelautan, Institut Teknologi Yogyakarta sebagai lembaga peneliti pertama bernaung serta kepada bapak/ibu staf dosen dan teman-teman yang terlibat dalam Kuliah Kerja Lapangan 1 tahun 2016.

Tabel 9. Implikasi Kebijakan.

Table 9. Policy Implications.

\begin{tabular}{|c|c|c|c|c|}
\hline No & $\begin{array}{l}\text { Strategi/ } \\
\text { Strategy }\end{array}$ & $\begin{array}{l}\text { Arah Kebijakan/ } \\
\text { Direction Policy }\end{array}$ & $\begin{array}{c}\text { Stakeholder yang } \\
\text { terlibat/ Stakeholder } \\
\text { involved }\end{array}$ & Keterangan/ Description \\
\hline \multicolumn{5}{|l|}{1} \\
\hline 1 & $\begin{array}{l}\text { Keberagaman sumber daya hayati } \\
\text { dan non hayati dapat } \\
\text { dikembangkan untuk menarik } \\
\text { banyak wisatawan agar berkunjung } \\
\text { ke Pantai Depok/ The diversity of } \\
\text { biological and non biological } \\
\text { resources can be developed to } \\
\text { attract more tourists to visit Depok } \\
\text { Beach. }\end{array}$ & $\begin{array}{l}\text { Penghijauan sepanjang } \\
\text { pantai kawasan Pantai } \\
\text { Depok/ Greening along } \\
\text { the coast of Depok } \\
\text { Beach }\end{array}$ & $\begin{array}{l}\text { Dinas Pertanian, } \\
\text { Pangan, Kelautan dan } \\
\text { Perikanan/ } \\
\text { Department of } \\
\text { Agriculture, Food, } \\
\text { Marine and Fishery In } \\
\text { Depok }\end{array}$ & $\begin{array}{l}\text { Di Pantai Depok terdapat } \\
\text { banyak tanaman cemara } \\
\text { udang namun keberadaannya } \\
\text { perlu ditambah sehingga dapat } \\
\text { menimbulkan rasa sejuk dan } \\
\text { sebagai penahan laju abrasi/ } \\
\text { Beach there are many shrimp } \\
\text { cypress plants but its existence } \\
\text { needs to be added so it can } \\
\text { cause a cool taste and as an } \\
\text { abrasion rate holder }\end{array}$ \\
\hline 2 & $\begin{array}{l}\text { Mengembangkan icon wisata dari } \\
\text { sumber daya yang ada di Pantai } \\
\text { Depok untuk untuk dijadikan } \\
\text { sebagai produk unggulan baru/ } \\
\text { Develop a tourist icon from the } \\
\text { resources that exist in Depok } \\
\text { Beach to be used as a new } \\
\text { flagship product }\end{array}$ & $\begin{array}{l}\text { Pengembangan olahan } \\
\text { ikan khas Pantai } \\
\text { Depok/ Development of } \\
\text { typical fish processing } \\
\text { Depok Beach }\end{array}$ & $\begin{array}{l}\text { Dinas Koperasi, } \\
\text { Usaha Kecil, } \\
\text { Menengah dan } \\
\text { Perindustrian/ } \\
\text { Department of } \\
\text { Cooperatives, Small } \\
\text { and Medium } \\
\text { Enterprises and } \\
\text { Industry }\end{array}$ & $\begin{array}{l}\text { Selain dikembangkan sebagai } \\
\text { olahan krispi, jenis ikan yang } \\
\text { ada di Pantai Depok dapat } \\
\text { dikembangkan menjadi olahan } \\
\text { siap saji seperti empek-empek } \\
\text { dan siomay yang dapat } \\
\text { langsung dinikmati oleh } \\
\text { wisatawan/ In addition to being } \\
\text { developed as processed krispi, } \\
\text { fish species in Depok Beach } \\
\text { can be developed into ready- } \\
\text { to-eat preparations such as } \\
\text { empek-empek and siomay that } \\
\text { can be directly enjoyed by } \\
\text { tourists }\end{array}$ \\
\hline 3 & $\begin{array}{l}\text { Pemerintah setempat harus } \\
\text { mendorong dan membantu } \\
\text { pembangunan daya tarik wisata } \\
\text { baru dari sumber daya hayati } \\
\text { maupun non hayati yang ada di } \\
\text { Pantai Depok/ The local } \\
\text { government should encourage and } \\
\text { assist the development of new } \\
\text { tourist attractions from biological } \\
\text { and non-biological resources in } \\
\text { Depok Beach }\end{array}$ & $\begin{array}{l}\text { Pembuatan taman } \\
\text { keluarga dan bermain/ } \\
\text { Family park building } \\
\text { and play }\end{array}$ & $\begin{array}{l}\text { Dinas Pekerjaan } \\
\text { Umum, Perumahan } \\
\text { dan Kawasan } \\
\text { Permukiman/ } \\
\text { Department of Public } \\
\text { Works }\end{array}$ & $\begin{array}{l}\text { Pembuatan taman dilengkapi } \\
\text { dengan areal bermain bagi } \\
\text { anak serta kursi kursi untuk } \\
\text { bersantai, fasilitas taman ini } \\
\text { dimaksudkan bagi wisatawan } \\
\text { agar mereka tidak hanya bisa } \\
\text { menikmati pantai tetapi juga } \\
\text { menikmati kesejukan udara } \\
\text { pantai/ Housing and } \\
\text { Settlement Area Gardening is } \\
\text { equipped with children's play } \\
\text { area and lounge chairs, garden } \\
\text { facility is meant for tourists so } \\
\text { that they not only can enjoy the } \\
\text { beach but also enjoy the cool } \\
\text { beach air. }\end{array}$ \\
\hline
\end{tabular}




\section{Lanjutan Tabel 9 /Continue Table 9}

\begin{tabular}{|c|c|c|c|c|}
\hline No & $\begin{array}{l}\text { Strategi/ } \\
\text { Strategy }\end{array}$ & $\begin{array}{l}\text { Arah Kebijakan/ } \\
\text { Direction Policy }\end{array}$ & $\begin{array}{c}\text { Stakeholder yang } \\
\text { terlibat/ Stakeholder } \\
\text { involved }\end{array}$ & Keterangan/ Description \\
\hline & & $\begin{array}{l}\text { Wisata memasak/ } \\
\text { Tourism cooking }\end{array}$ & $\begin{array}{l}\text { Dinas Pariwisata/ } \\
\text { Tourism Office }\end{array}$ & $\begin{array}{l}\text { Wisata ini memberikan } \\
\text { peluang kepada wisatawan } \\
\text { untuk memasak olahan ikan, } \\
\text { misalnya wisatawan membuat } \\
\text { olahan ikan krispi/ This tour } \\
\text { provides opportunities for } \\
\text { tourists to cook processed fish, } \\
\text { such as tourists making } \\
\text { processed fish krispi. }\end{array}$ \\
\hline
\end{tabular}

Pengolahan produk sumber daya hayati dilaksanakan oleh anggota koperasi dan didukung oleh pemerintah setempat melalui pelatihan/bantuan alat dan bahan/kemudahan pinjaman/ Processing of biological resources products implemented by cooperative members and supported by local government through training / aid of tools and materials / ease of lending

Pengolahan ikan
menjadi frozen food
oleh kelompok
masyarakat/ Fish
processing into frozen
food by community
groups

Pelatihan pengolahan frozen food/ Training on frozen food processing for

for Cooperatives, Small and Medium

Enterprises and Industry

Pelatihan pengemasan produk/ Training on product packaging

Pelatihan pemasaran produk/ Product marketing training

Penataan pedagang oleh-oleh dan kaki lima/ Arrangement of merchant souvenirs and street vendors
Dinas Koperasi, Usaha Kecil, Menengah dan Perindustrian/ Department of Cooperatives, Small and Medium

Dinas Koperasi, Usaha Kecil, Menengah dan Perindustrian/ Cooperatives, Small and Medium Enterprises and Industry

Dinas Koperasi, Usaha Kecil, Menengah dan Perindustrian/ Cooperatives, Small and Medium Enterprises and Industry

Dinas Koperasi, Usaha Kecil, Menengah dan Perindustrian/ Cooperatives, Small and Medium Enterprises and Industry

Dinas Pekerjaan Umum, Perumahan

dan Kawasan government has arranged Depok Beach Area
Department of Public Works, Housing and Settlement Area
Makanan yang dibekukan seperti nugget, bakso bisa menjadi alternatif untuk buah tangan wisatawan/ Enterprises and Food Industry frozen like nuggets, meatballs can be an alternative to fruit hand tourists
Keberadaan pedagang oleholeh dan kaki lima sangat banyak dan masih belum tertata. Pengaturan lokasi bagi pedagang akan memberikan kenyamanan bagi wisatawan/ The existence of traders souvenirs and pavement are very much and still not organized. Setting the location for the merchant will provide comfort for tourists 


\section{Lanjutan Tabel 9 /Continue Table 9}

\begin{tabular}{|c|c|c|c|c|}
\hline No & $\begin{array}{l}\text { Strategi/ } \\
\text { Strategy }\end{array}$ & $\begin{array}{l}\text { Arah Kebijakan/ } \\
\text { Direction Policy }\end{array}$ & $\begin{array}{c}\text { Stakeholder yang } \\
\text { terlibat/ Stakeholder } \\
\text { involved }\end{array}$ & Keterangan/ Description \\
\hline 6 & $\begin{array}{l}\text { Melakukan budidaya terhadap jenis } \\
\text { ikan tertentu/ Conducting } \\
\text { cultivation of certain types of fish }\end{array}$ & $\begin{array}{l}\text { Budidaya ikan laut } \\
\text { dengan menggunakan } \\
\text { bak fiber dan } \\
\text { menggunakan teknologi } \\
\text { yang ramah lingkungan/ } \\
\text { The cultivation of } \\
\text { marine fish using fiber } \\
\text { and using } \\
\text { environmentally friendly } \\
\text { technology }\end{array}$ & $\begin{array}{l}\text { Dinas Pertanian, } \\
\text { Pangan, Kelautan dan } \\
\text { Perikanan/ } \\
\text { Agricultural, Food, } \\
\text { Marine and Fishery } \\
\text { Service Office }\end{array}$ & $\begin{array}{l}\text { Budidaya ikan laut (misal } \\
\text { seperti ikan kakap dan kerapu) } \\
\text { dimaksudkan untuk } \\
\text { kepentingan wisata kuliner } \\
\text { yang sangat berkembang di } \\
\text { Pantai Depok. Budidaya ikan } \\
\text { dengan teknologi ramah } \\
\text { lingkungan ini tidak merusak } \\
\text { ekosistem sand dune/ Marine } \\
\text { fish farming (eg, snapper and } \\
\text { grouper) is intended for the } \\
\text { culinary interest that is highly } \\
\text { developed in Depok Beach. } \\
\text { Fish cultivation with } \\
\text { environmentally friendly } \\
\text { technology does not damage } \\
\text { the sand dune ecosystem }\end{array}$ \\
\hline
\end{tabular}

Sumber: Analisis, 2016/Source: Analysis, 2016

\section{DAFTAR PUSTAKA}

Dahuri, R., J. Rais., S. P. Ginting dan M.J. Sitepu. 2004. Pengelolaan Sumberdaya Wilayah Pesisir dan Lautan Secara Terpadu. Pradnya Paramita, Jakarta, $305 \mathrm{hlm}$.

Fandeli, C. 2002. Perencanaan Kepariwisataan Alam. Yogyakarta: Fakultas Kehutanan UGM.

Haryanti, S., A. Setyaningrum dan E. Masduqi. 2015. Penelitian Studi Kebutuhan Ikan di Pantai Depok Yogyakarta. Yogyakarta: Institut Teknologi Yogyakarta.

Nawawi, A. 2013. Partisipasi Masyarakat dalam Pengelolaan Wisata Pantai Depok di Desa Kretek Parangtritis. Jurnal Nasional Pariwisata. Volume 5 No 2, Agustus 2013 Halaman 103-109.

Sahubawa, L. 2015. Kajian Sebaran Potensi Ekonomi Sumber Daya Kelautan di Pantai Selatan Daerah Istimewa Yogyakarta sebagai Upaya Percepatan Investasi. Jurnal Tekno Sains. Volume 4 No 2, 22 Juni 2015 Halaman 101-198.

Saputra, E. 2010. Materi Kuliah Perencanaan Pengembangan Pariwisata. Yogyakarta: Fakultas Geografi UGM.

Setyorini, H. B., E. Rahayu dan S. T. Putro. 2015. Karakteristik Nelayan Di Pantai Depok, Bantul, Yogyakarta. Seminar Nasional Tahunan XII Hasil Penelitian Perikanan dan Kelautan, 08 Agustus 2015, pSE-02: 697-704.
Setyorini, H. B. dann A. Setyaningrum. 2016. Penelitian Sumber Daya Kelautan untuk Menunjang Kegiatan Pariwisata di Pantai Depok Daerah Istimewa Yogyakarta. Yogyakarta: Institut Teknologi Yogyakarta.

Supriyati dan H. Tarigan. 2008. Meningkatkan Nilai Tambah melalui Agroindustri. Warta Penelitian dan Pengembangan Pertanian. Volume 30 No 4 tahun 2008.

Undang-Undang No.10 Tahun 2009 tentang Kepariwisataan.

World Tourism Organization (WTO). 2013. Sustainable Tourism for Development Guidebook. Madrid : Sustainable Tourism for Development. 